\title{
LITERATURA, ENSINO E DEMOCRACIA: APONTAMENTOS SOBRE A CRISE
}

LITTÉRATURE, ENSEIGNEMENT ET DÉMOCRATIE: NOTES SUR LA CRISE

Luiz Henrique Carvalho

Penido*

\author{
luizpenido@gmail.com \\ Professor na Universidade Estadual de Montes Claros (Unimontes). \\ Doutor em Estudos Literários pela Universidade Federal de Minas
Gerais (UFMG).
}

RESUMO: Este artigo tem por objetivo levantar questões sobre a singularidade do texto literário, os modelos disciplinares escolares e a sua relação com a

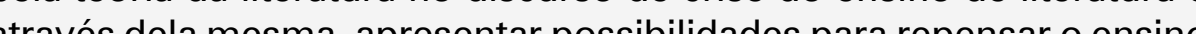
A hipótese que nortéa nossa ańlise passa pela capacidade da literaA hip para solicitar os persistentes fundamentos herdados dos modelos

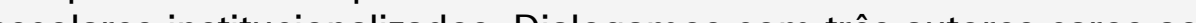
escolares itrérics - Rolind Barthes, Michel Foucault e Jacques Des aos empre buscando ovinculo enteo singular liteŕt e Jac condic̃os de

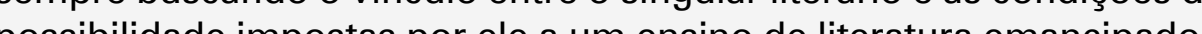

PALAVRAS-CHAVE: ensino; literatura; democracia; crise.

RESUMÉ: Cet article vise à soulever des questions sur la singularité du texte littéraire, les modèles disciplinaires scolaires et sa relation avec la démocratie Nous essayons de comprendre le rôle hérité par la théorie de la littérature dans le discours de crise de l'enseignement de la lit-

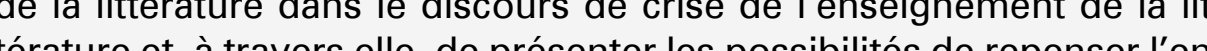

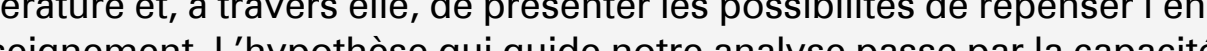
de la littérature à solliciter les fondements persistants hérités des modè la litution trois auteurs importionts pour les études littéraires Miches singulier littéraire et les conditions de possibilité imposées par lui à un singulier litteraire et les conditions de possibilite imposées par lui a

MOT-CLÉS: enseignement; littérature; démocratie; crise 
1. Compagnon demarca os anos mais prolíficos de avanço na teoria francesa entre 1963, fim da guerra da Argélia, e 1973, com o primeiro choque petroleiro. (1999, p. 12) Nesse período a teoria francesa viveu seus anos contestatorios e triunfantes, disseminando-se,
Assim, quanto mais livre for esse ensino, tanto mais será necessário indagar-se sob que condições e segundo que operações o discurso pode despojar-se de todo desejo de agarrar. Esta interrogação constitui, a meu ver, o projeto profundo do ensino que hoje se inaugura.

Aula, Roland Barthes

A epígrafe é de uma ironia fundamental. Prepara, antes mesmo de colocarmos em movimento nosso discurso, as irrisões e expiações que a travessam as relações entre teoria literária e ensino de literatura na segunda metade do séc. $X X$. Se nos for permitido, podería mos ir além e a firmar que a epígrafe acima - topos de acesso à cadeia conceitua daquilo que podemos chamar imprecisamente teoria literária ou simplesmente teoria quando pensa mos nos prolífico e agitados anos 60 e 70 na França ${ }^{1}$ - em sua dimensão epistemológica explicita ao pensamento teórico as condições da reflexão sobre a prática docente. Haveria, segundo essa perspectiva, um ensino livre, despojado de todo desejo de poder - ensino fantasmático porque ainda por vir necessaria mente sempre por vir - e outro, marcado pelas sobreterminações das instituições, dentre elas os institutos escolar e universitário. Tal afirmação advém do fato de que Barthes, assim como vá rios outros teóricos seus contemporâneos, entende por literatura "não um corpo ou uma sequência de obras, nem mesmo um setor de comércio ou de ensino, mas o grafo complexo das pegadas de uma prática: a prática de escrever". ${ }^{2}$ Com essa conhecida afirmação, separa-se o ensino de literatura entre dois possíveis encaminhamentos, o tradicional e o novo, em outras palavras, o do cânone literá rio em sua forma escolarizada e esvaziada e o da escrita democrática da palavra emancipada através do singular literá rio. ${ }^{3}$ A litera tura, propriamente dita, estaria pendida entre essas duas formas de agenciamento que corresponderiam, por sua vez, aos aliciamentos do espaço docente institucional e às subversões teóricas de um exercício de leitura-escrita fora do poder.

Tomaremos, então, seu posicionamento estrategicamente como leitmotiv neste artigo. Em Barthes, a teoria cogita em todas as suas consequências as potências operadas pela linguagem literária. "Essa trapaça salutar, essa esquiva, esse logro magnífico que permite ouvir a língua fora do poder no esplendor de uma revolução permanente da linguagem" ${ }^{4}$, no entanto, corre sempre o risco de pertencer mais ao esteta do que ao leitor comum, alcançar mais o pesquisador-escritor imerso em um ambiente onírico de especulação do que a multidão dos leitores anônimos em suas idiossincrasias particulares e determinismos sócio históricos. Isso pois a passagem da literatura ao ensino acontece sob a ameaça de destruir o objeto ao acessá-lo, de esvaziá-lo ao pretender oferece-lo à leitura. Ensino de literatura e teoria literária,
3. Por singularidade entenda-se não o conceito de literariedade legado pelo formalismo russo, mas a maneira única da literatura de forja uma linguagem fora do poder, ou ainda, seu caráter emancipador como ficará claro, esperamos, longo da exposição.

4. BARTHES, Aula, p. 16 .

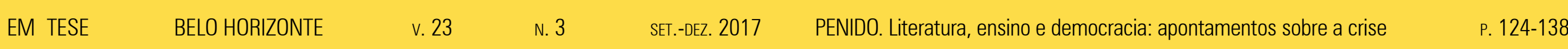


5. Jacques Derrida, em seus últimos escritos, percebe algo semelhante, nesse caso a distância entre o rigo e a prática/intervenção política efetiva.

6. BARTHES, Escritores, Intelectuais, Professores e outros ensaios, 1975 isto nos sugere Barthes e sobre isso trataremos, sofrem de uma incompatibilidade de fato e de direito, ${ }^{5}$ pois apresentam duas versões distintas da litera tura, duas maneiras de abordagem do literário incompatíveis: do lado da teoria, discurso pretensamente capaz de apagar as formas do poder, impoder essencial da democracia das letras; de outro, do lado das instituições escolares, texto que serve às práticas docentes, meio de se atingir um fim político-pedagógico simultâneo ao esvazia mento do singular literário. A questão do ensino, nos parece, está no cerne da sua aula inaugural na Sorbonne e de outros textos seminais como "Escritores, intelectuais, professores", sempre solidificando a ambivalência da literatura conforme seja objeto teórico, objeto de fruição do leitor privilegiado ou meio de controle do a nônimo subjugado. Trata-se então de pensar como conciliar os irreconciliáveis, a rigorosa teoria literária e as instituições, a literatura e a escola, ou, ainda mais crítico e urgente, repensar o ensino de modo a espoliá-lo dos traços que, paradoxalmente, fazem dele uma prática institucionalizante e diluidora. Utopia cravada no exato lugar em que se encontram a força coerciva das instituições e o poder de dissenso da escrita literária.

O objetivo a que nos propomos então é a nalisar, partindo de alguns breves apontamentos sobre a literatura e o ensino em três autores, a saber Roland Barthes, Michel Foucault e Jacques Derrida, como a teoria literária, em particular a de ascendência francesa - desde meados dos anos 70 do séc. XX a de maior penetração no âmbito universitá rio das Letras $^{7}$ - lidou com os problemas relacionados ao ensino de literatura. Responsáveis diretamente pelo florescimento de um pensamento teórico ora combativo e polêmico, ora de minuciosa exegese, inva riavelmente ligados ao vigor singular da linguagem literária, permitem analisar as distâncias e embates entre teoria e ensino. Invenções de uma década e meia revolucionária, as teorias desse período apesar de permanecerem entre nós cinquenta a nos depois, fora m pouco solicitadas quando se trata do impasse central acionado por elas: como conciliar a liberdade da palavra com a coerção da polícia das letras, isto é, a abertura literária e a escola enquanto ente estatal dedicado ao exercício do poder.

Tal diagnóstico é importante porque, excluídas algumas iniciativas, percebemos atualmente o desinteresse por tais reflexões, muitas vezes disfarçado pelo diagnóstico, acertado, porém parcial, de uma crise da literatura - crise da cultura em seu sentido mais amplo, incluída a versão oficial escolar. O desinteresse a tual é, sem dúvida, sintoma do esvazia mento ta mbém do discurso teórico, convertido em heurística ou curiosidade obriga tória nos cursos de Letras, motivando o abandono das questões docentes a áreas afins como a linguística aplicada e a pedagogia.

De fato, tendo a literatura por objeto privilegiado, os herdeiros da teoria literária foram incapazes de desenvolver
7. A criação dos cursos de pósgraduação nos anos 80 por em universidades europeias dá testemunho disso em nosso contexto nacional. 
uma reflexão profunda sobre as singularidades de seu ensino, a começar pela do seu próprio objeto, a literatura Aberta essa lacuna, desenvolveram-se práticas pedagógicas sustentadas em teorias textuais provenientes dos estudos linguísticos, em que a especificidade do literário e a maneira de modalizar a língua de dentro, foram substituídas por processos de textualização a mpla. Resultado ta mbém, é importante mencionar, da abertura genérica dos planos curriculares que passaram a adotar textos das mais variadas ordens em uma preocupação de fundo político sociológica que apaga as distinções do específico literário. No mesmo movimento, o que ainda restava de específico das teorias literárias converteu-se em reduções ou adaptações que aplainam preocupações complexas para que possam ser aplicadas na prática diária docente - a estética da recepção é um dos alvos preferidos na atualidade, semelhante ao que foi o efeito tranquilizador do estruturalismo no exercício docente no final do século passado, até o esgotamento desse modelo -, reforçando muitas vezes o vínculo equivocado entre teorias e métodos de análise. A 'escolarização’ programática de nomes como Gerard Genette e Tzvetan Todorov demonstra claramente esse processo redutor.

Não se trata, óbvio, de recusar os avanços das preocupações de ordem ética dos Estudos Culturais nem ignorar as importantes mas, acreditamos, ainda limitadas contribuições da teoria literária para o ensino, pelo contrário, gostaría mos de analisar os motivos que levaram a teoria literária nos dias atuais, a despeito das preocupações iminentes qua nto ao ensino no período de maior combatividade, a se eximir frequentemente de uma maior preocupação referente ao assunto e como esse afastamento contribuiu para inflacionar o discurso da crise da literatura sem, no entanto, intervir propositivamente no campo. De fato, a atenção para a tensão permanente entre as instituições escolares tradicionais e a busca de um ensino de literatura com características ema ncipadoras demonstra, a princípio, que é através da própria literatura e das questões que ela levanta que os modelos institucionais devem ser repensados, o que significa, ainda, teorizar com a litera tura. Também pretendemos apontar, no interior dessa mesma teoria, caminhos para desfazer esse impasse que tanto mal faz a um já precarizado ensino.

\section{BARTHES E O MAIO DE 68}

Encontraremos um antecedente que explica em grande medida esse estado de coisas no período de maior efervescência teórica e política e que, até hoje, repercute no a mbiente das humanidades: os a nos que seguiram ao Maio de 68. A aversão às instituições desenvolvida na esteira dos movimentos revolucionários, funcionando como pano de fundo das insurgentes reflexões dos autores do período

\begin{tabular}{|c|c|c|c|c|c|}
\hline EM TESE & BELO HORIZONTE & v. 23 & N. 3 & SET.-DEZ. 2017 & PENIDO. Literatura, ensino e democracia: apontamentos sobre a crise \\
\hline
\end{tabular}


8. RANCIĖRE, O prazer da metamorfose política, p. 27 afastou sobremaneira a teoria, em especial a fundada no literário, considerada revolucioná ria e antiinstitucional, dos espaços oficiais de ensino, qualificados braços de violência simbólica do estado. Havia àquele tempo uma desconfia nça generalizada em relação a todas as formas de cooptação representadas pelos entes estatais. Não por acaso, a maior parte das ações orquestradas no período se deu com a ocupação de espaços oficiais - inicialmente a Université Pa ris Nanterre, em seguida a Sorbonne, até a explosão de uma greve geral tomando as ruas com adesão de mais de dois terços do operariado. Rancière nos lembra que "68 colocou em primeiro plano toda uma outra ideia de política: a criação de espaços que não se identificam nem com a gestão das instituições existentes, nem com a formação de uma vanguarda para a revolução que virá"». Tratava-se ali de uma tensão entre poderes oficiais e impoderes a nônimos, entre o conceito das instituições oficiais e contrapoderes horizontalizados que se recusavam a participar do jogo político tradicional. É natural que os teóricos do período percebessem nas instituições que fazem uso do específico literário, dentre elas a universidade tradicional e a escola de formação básica, uma fábrica coerciva, o domínio repressor da Lei, isto é, nelas, a literatura se apresentaria como um texto castrado e reduzido à heurística ideologicamente interessada, despida de sua potência mobilizadora, solicitadora.
Posicionar a literatura enquanto língua fora do poder é antes de tudo uma estratégia política indispensável, tal qual recusar-se a qualquer forma de institucionalização. A literatura e a teoria literária representando a escrita continuada (écriture), pensa Barthes e a órbita teórica de sua reflexão, permitiriam ouvir essa língua fora do poder ao mesmo tempo que suprimiriam os seus efeitos nos discursos. ${ }^{9}$ Era impraticável, assim, naquele momento histórico, conciliar o impoder a tribuído à litera tura com as instituições, o Estado, a Lei, a Escola; a face combativa da teoria literária com o ensino formal, uma vez que este último se erigia no lugar de máxima contestação dos movimentos revolucionários. Tratava-se de uma denegação profunda das instituições, contribuindo imensamente para o posterior descrédito, principalmente após o fracasso revolucionário, da reflexão sobre o ensino, esta última enquadrada nas pantominas de cooptação do estado, em um alardeado assassina to da literatura.

Por isso o caráter a mbivalente da aula ina ugural de Barthes em 1977, a tensão entre a honra recebida e o engajamento da Semiótica na contramão do poder ali estabelecido. Ao longo de seu pronunciamento ele coloca sob suspeita mais de uma vez a relação entre ensino e literatura na condição de acesso paradoxalmente privilegiado que a concessão da cadeira de Semiótica permitia a ele. O Collége
9. A literatura nesse artigo é tratada de forma geral, enquanto escrita órfã com força emancipadora na acepção de Rancière. No entanto, é importante pontuar que tanto ele quanto os autores do periodo privilegiaram obras e autores de épocas variadas que compartilhavam certo ethos escritural oposto às ideias de cânones, normas ou escolas.

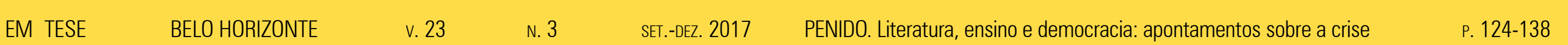


de France, ao qual ele se dirigia naquele momento, seria, eis a ironia, uma das últimas "astúcias da História" ${ }^{10}$ capaz de oferecer uma fala fora da submissão ao saber dirigido, o lugar da subtração do poder. Assim, das inúmeras menções ao ensino de literatura no pronunciamento, a quase totalidade se dirigia a construir uma distinção entre o que se começava a fazer ali e agora, naquele espaço de subtração, e o que se fazia e se continuava a fazer alhures e ou antes, em que os textos literários era $\mathrm{m}$ capitalizados por uma prática deletéria atribuída aos entes institucionais e às sobras de poder. A literatura penderia entre dois mundos: o da pesquisa-fala do leitor privilegiado do Collége e aquele do ensino-lei-ordenação do docente comum submetido ao sistema regular. Barthes estabelecia-se, quase uma década após o Maio de 68, no centro da polêmica assinalada por seus próprios apontamentos: negava assumindo as honras do poder, assumia o impoder dissuadindo-se de sua associação.

A urgência profunda dessa denegação-assunção é que ela legitima aquilo que pretende negar: a aula inaugural afirma que a literatura é algo que se ensina, que se presta ao ensino, tem lugar entre as práticas docentes, é um objeto escolar passível de determinada transmissão de ideias, formas, convenções, a nálises, procedimentos etc. A literatura na sala de aula se prestaria à atividade do professor - seja a fala o resumo, a autoridade da asserção, o método, todas elas atividades questionadas ${ }^{11}$ - validando seu lugar no rol das disciplinas e o interesse teórico-pedagógico inarredável. O posicionamento de Barthes nesse texto específico se transforma em problema, pois o horror às instituições deveria elevar precisamente o interesse pelo uso que essas mesmas instituições fazem das obras literárias - parece-me um dos caminhos legítimos que ele esperava abrir ao Collége, não fosse a morte precoce em 1980.

Barthes nos parece dizer nesse texto que eximir-se do jogo das instituições acarretaria o risco de fracassar as possibilidades de intervenção verdadeira mente revolucionárias da teoria in loco. Pois, se a literatura, enfim, serviu à escola sob as condições de uma modalização político-pedagógica de que ainda não testemunhamos totalmente as consequências, mas que se fazem presentes no seu gradativo enfraquecimento em meio à proliferacão dos usos sócio-funcionais da palavra - a alardeada crise da literatura que a reduz à va riável da língua e não mais a uma maneira especial de mobilizar a linguagem - cumpriria ao discurso teórico apontar essas fissuras e reducionismos. Quase uma década depois do Maio de 68 e seus contrapoderes - nou sommes tous indésirables ${ }^{12}$ - caberia sobremaneira a denúncia dos redutores escolares e, por isso mesmo, o esforço de se repensar o elo entre "essa estranha instituição chamada literatura" ${ }^{\prime 13} \mathrm{e}$ as instituições propriamente ditas que se
11. BARTHES, Escritores, Intelectuais, Professores e outros ensaios, p. 25-61.

12. Frase de um dos cartazes elaborados pelo Atelier Populaire em Maio de 68.

13. Menção ao livro de Derrida, assunto deste ensaio na terceira parte.

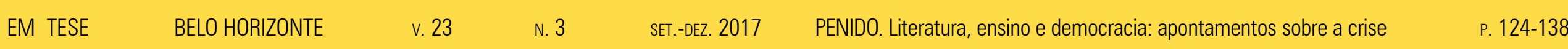


utilizam da sua palavra. Ali se iniciaria a tarefa de Barthes: desconstruir de dentro o Collége na e pela literatura.

\section{O DISCIPLINAMENTO: FOUCAULT}

Enquanto as preocupações de Barthes enfatizavam o singular literário, a especificidade própria da literatura se opondo às instituições e à institucionalização escolar, forjando um espaço intencionalmente fora do poder - é pela língua que se experimenta a indocilidade - Foucault traçará alguns parâmetros importantes para pensar a passagem da literatura ao ensino. Em Vigiar e Punir, livro dedicado a analisar as astúcias do poder disciplinador, Foucault descreve como o novo poder disciplinar surgido nos séculos XVII e XVIII substitui a ingerência sobre a posse de terras e ferramentas pelo disciplinamento dos corpos. A escola, dentre as instituições do estado, está ao lado dos sanatórios, dos campos de concentração e das prisões ao aplicar técnicas de docilização do corpo do indivíduo com o objetivo de fazê-lo cumprir determinadas rotinas úteis ao funcionamento do mecanismo oficial. Não há, segundo sua concepção, um poder único, mas poderes que se exercem através do controle das atividades.

Quanto à arte das distribuições, é preciso: a) definir um espaço heterogêneo e cercado de encarceramento que se distingue dos outros; b) quadricular esse espaço de modo a definir os lugares e distribuir os corpos; c) observar as localizações funcionais de modo a criar espaços úteis; $d$ ) finalmente, tornar interca mbiáveis os espaços permitindo a serialização da disciplina. Quanto ao controle das atividades: a) o horário, esquadrinhado ao limite nas escolas elementares torna-se cada vez mais esmiuçante e controlado a fim de organizar uma temporalidade "integralmente útil", virtude fundamental do "tempo disciplinar"14; b) é imposto ao escolar, nos moldes militares, a ordenação rítmica das atividades, "ritmo coletivo e obriga tório, imposto do exterior" ${ }^{15}$; c) correlação entre gesto e o corpo visando a máxima eficácia passa a definir a atitude global requerida na ordem das instituições "Uma boa caligrafia, por exemplo, supõe uma ginástica”" ${ }^{16}$ d) a relação corpo e objeto passa a ser disciplinada, o que ele cha ma codificação do corpo e corresponde à complexa sintaxe entre as partes do corpo e os elementos dos objetos - nas escolas a relação coreografada entre a pena, o papel (o livro) e a postura; e) enfim, também é essencial o princípio da não-ociosidade, "é proibido perder um tempo que é contado por Deus e pago pelos homens" ${ }^{17}$, princípio de produtividade por excelência. O conjunto desses pequenos e estratégicos disciplinamentos forma o horizonte geral herdado pela escola do século XX na qual o objetivo é "compor forças para obter um aparelho eficiente" 18 . Tais efeitos de dominação disseminados em redes atravessando os corpos socia is ponderam as relações
14. FOUCAULT, Vigiar e punir, p. 176177.

15. FOUCAULT, Vigiar e punir, p. 177

16. FOUCAULT, Vigiar e punir, p. 178

17. FOUCAULT, Vigiar e punir, p. 178

18. FOUCAULT, Vigiar e punir, p. 189

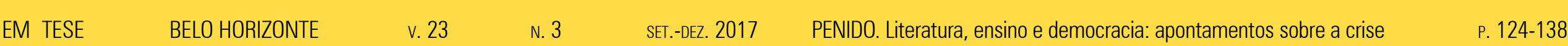

Ensino de Literatura 
19. FOUCAULT, Vigiar e punir, p. 31

20. FOUCAULT, Estética, literatura e pintura, música e cinema, p. 48. entre saber e poder. Foucault não acredita haver um espaço onde o poder estaria suspenso permitindo o desenvolvimento do saber livre e operante, pelo contrário, saber e poder estão absolutamente implicados, "o poder produz saber", em outras palavras é o "poder-saber, os processos e as lutas que o a travessam (o sujeito do conhecimento) e que o constituem, que determinam as formas e os campos possíveis do conhecimento" ${ }^{19}$.

Sob esse horizonte do disciplinamento operado no ambiente escolar cabe-nos perguntar sobre a passagem da literatura ao ensino, ou melhor, as consequências de uma passagem de fora do poder - instância sob a qual Barthes denuncia sem o querer em sua a mbiguidade - e o disciplinamento escolar produzindo formas de saber marcadas pelas balizas de suas táticas e procedimentos, o "poder-saber”. Para tanto é necessário compreender a concepção de literatura em Foucault para então passar à apropriação disciplinar.

Foucault em "A linguagem ao infinito", texto de 1963 influenciado confessadamente por Blanchot, demarca a injunção funda mental entre a palavra e a morte. A palavra enqua nto linguagem continuada, infinita, articula o duplo a través do qual o indivíduo afasta a sua morte, descobrindo o rela to do rela to quando faz "nascer em si mesma sua própria imagem em um jogo de espelhos que não tem limites" ${ }^{20}$.
A saga do herói cede o exemplo dessa relação: quando confrontado com o relato de sua morte, Odisseu chora ao perceber-se convertido em palavra morta e, ao mesmo tempo, se insurge contra essa narrativa acrescentando o suplemento de rela to capaz de celebrar e afirmar-se contra esse estado, isto é, ele continua a narrar postergando e colocando além o vínculo entre a narrativa e sua própria morte, permanece vivo no sopro tênue do dizer. Foucault conjectura, assim, haver "um parentesco essencial entre a morte, a continuidade ilimitada e a representação da linguagem por ela mesma" ${ }^{21}$, confirmando, nesse sentido, a trivalência da narrativa infinitamente em movimento. Ora, no séc. XVIII uma mudança se produz, momento em que nasce aquilo a que chama mos literatura. Volta à origem e fundo da linguagem que se anuncia, a invenção do literário permite avançar indefinidamente fora dos circuitos do mesmo, rejeitando a contenção operada na regulação dos sentidos: a esse fenômeno damos o simples nome de escrita. De fato, o diagnóstico de Foucault relativo a uma mudança plena de significações porque traz à superfície o vínculo da palavra com sua origem, isto é, a literatura como a conhecemos hoje, retoma em termos barthesia nos o vínculo entre literatura e as práticas de escrita. Rancière, a propósito da mesma questão, afirmava que a literatura "não é aquilo que sucede às belas-letras, porém aquilo que as suprime. Há literatura quando os gêneros poéticos e as
21. FOUCAULT, Ditos e escritos V. III. p. 48

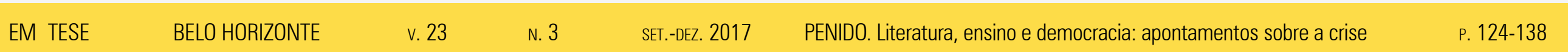

Ensino de Literatura 
22. RANCIÈRE, Políticas da escrita, p. 28-29. a rtes poéticas cedem lugar ao ato indiferenciado e à arte singular de escrever"22.

Coincidência interessante: a passagem do poder centralizado sobre a posse de bens às técnicas disciplinares corres ponde à passagem das belas-letras à literatura, o saber dos letrados para a prática indiferenciada de escrever, o saber tradicional para o não-saber impoder da escrita. O instante em que as instituições disciplina res esquadrinham os corpos, os gestos, os encontros - parentesco entre a prisão, o manicômio e a escola, isto é, entre a aplicação da ordenação, da normalização e do assujeita mento -, demarcando as condições de possibilidade do poder-saber, coincide ponto a ponto com a substituição do erudito pela figura do escritor, das normas da boa escrita pela idiossincrasia dos indivíduos, do cultivo dos gêneros pelo trânsito da escritura que difere infinitamente de si. Incapaz de controlar a proliferação da palavra abandonada por um pai, um pastor, um autor apto a conter a proliferação dos sentidos, as instituições articula m procedimentos, estratégias, formas de assimilação com o intuito de regular os encontros e assujeitar os indivíduos sob sua tutela. A instituição escolar representa a contraforça da literatura, porque submete e modaliza suas possibilidades de emancipação através do disciplinamento dos corpos.
Assim, a arte das distribuições analisada em Vigiar e Punir se choca frontalmente com a leitura-escrita literária: a) há injunção entre o corpo e a atividade de leitura-escrita, esta experimenta o esgarçamento das fronteiras porque mobiliza tanto um processo fisiológico em que o corpo é entregue à disponibilidade do ato de leitura ocioso em uma presença não-presente quanto sua virtualização por meio do acionamento de processos cognitivos, afetivos e simbólicos. O encarceramento físico na sala de aula, a serialização dos corpos dispostos em filas, a leitura controlada e coletivizada, a escrita limitada aos gêneros escolares bem definidos visa, exatamente, conter as potências da leitura silenciosa e idiossincrática; b) esquadrinhar e distribuir os corpos demarca os papeis, sanciona as ações, organiza um espaço analítico negando as zonas cinzentas de indecidibilidade, em tudo contrário à vertigem da letra escrita, para a qual não há autoridade ou subserviência mas abertura aos indecidíveis; c) dotá-lo de localizações funcionais, enfim, depõe contra a experiência aberta do impoder da palavra escrita, isto é, tomando-se a biblioteca como modelo absoluto de tais localizações, a literatura entregue à aventura da escrita é uma economia anti-ordenatória já que as unidades funcionais - o espaço, a seção, o livro, a coleção - colocados em movimento pelo ato de leitura, perdem sua funcionalidade e localização, abrindo-se, de novo, ao avanço infinito da linguagem; d) o mesmo podemos compreender da

\begin{tabular}{|c|c|c|c|c|c|}
\hline EM TESE & BELO HORIZONTE & v. 23 & N. 3 & SET.-DEZ. 2017 & PENIDO. Literatura, ensino e democracia: apontamentos sobre a crise \\
\hline
\end{tabular}


serialização interca mbiável, em que a economia definida de trocas age contra a ecografia dos contágios.

O mesmo se dá quanto ao controle da atividade: a) o controle da temporalidade contra a leitura-escrita fundadora de temporalidade e simulta neamente supressão do tempo cronológico; b) a coreografia oficial contra a dotação singular da temporalidade, corrigida no acaso do encontro com a palavra; c) a ginástica de micro procedimentos que envolve o ato próprio de excelência contra a leitura-escrita tomada de intermitências inajustáveis, atos solitários inventando a própria temporalidade e rítmica; d) a relação corpo e objeto, fundada na disciplinamento escolar da postura vigiada contra as atividades propriamente livres de leitura desinteressada representadas no indivíduo liberto dos laços coletivos; e) enfim, a economia escolar da funcionalidade e do tempo-valor contra a ociosidade, princípio essencia para que a escrita, a literatura avance indefinidamente.

\section{ESSA ESTRANHA INSTITUIÇÃO: LITERATURA E}

\section{DEMOCRACIA}

Tudo leva a crer que o ensino de literatura não terá melhores dias enquanto se insistir no modelo escolar apontado por Foucault, fundado na arte da distribuição e no controle da atividade. Apesar de serem reflexões preliminares, tentamos mostrar como a invenção da ideia de literatura no séc. XVIII coincide com a ascensão e recrudescimento dos modelos institucionais disciplinares, interferindo na distribuição dos corpos e na ingerência do tempo, procedimentos frontalmente contrários ao a to de leitura-escrita implicado no texto literário. Compete agora, após passar por Barthes e Foucault, repensar como o ensino de literatura, através dos apontamentos destacados aqui, pode ser desconstruído de dentro, liberando as possibilidades de uma modalização não totalmente castradora - pois se trata de um limite potencial nunca alcançável, sempre aberto. Derrida, a propósito da literatura, nos dá algumas pistas:

O espaço da literatura não é somente o de uma ficção instituída, mas também o de uma instituição fictícia, a qual, em princípio, permite dizer tudo. Dizer tudo é, sem dúvida, reunir, por meio da tradução, todas as figuras umas nas outras, totalizar formalizando; mas dizer tudo é também transpor [franchir] os interditos. É liberar-se [s'affranchir] - em todos os campos nos quais a lei pode se impor como lei. A lei da literatura tende, em princípio, a desafiar ou a suspender a lei. Desse modo, ela permite pensar a essência da lei na experiência do "tudo por dizer". É uma instituição que tende a extrapolar [déborder] a instituição. ${ }^{23}$

A literatura para o autor, consequência também do compartilhamento desse conceito de escrita (écriture) que
23. DERRIDA, Essa estranha instituição chamada literatura, $\mathrm{p}$

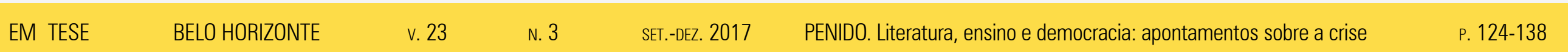

Ensino de Literatura 
acompanha a invenção da literatura em detrimento das belas-letras, é precisamente a instituição que dá o 'poder' de dizer tudo, colocando em suspeita os pares que regem a economia geral entre natureza e lei convencional, natureza e história e, claro, natureza e instituição. Como instituição que tende a extrapolar a instituição, a literatura é tanto aquilo continua mente a tacado pelos espaços institucionais - é preciso subjugar, disciplinar, ordenar - quanto aquilo que desborda da instituição - a literatura, permitindo tudo dizer, desregula os lugares, as funções e as hierarquias.

Ainda uma última coincidência repleta de sentido: assim como a passagem das belas-letras à literatura instigou os modelos institucionais disciplinares a intensificar os procedimentos de vigilância sobre o corpo tolerando a letra apenas quando submetida à delimitação de um poder-saber, isto é, um saber produzido pela regulação dos poderes, a literatura acompanha necessariamente a forma da democracia. A literatura, enqua nto escrita abandonada ao jogo, é a democracia das letras. Dois episódios dão a dimensão desse aspecto bem antes de se consolidar no séc. XVIII.

O primeiro advém do fato de que a separação original entre política e poética tenha se dado de forma inaugura e fundadora no âmbito de uma reflexão sobre o Estado na República de Platão. Mais especificamente, que os poderes atribuídos à má poesia sejam precisamente aqueles da democracia desmedida, da ausência de especializações, da confusão e reversibilidade das vozes. Em Platão, a democracia é o governo da confusão precisamente por destituir o pastor, seja ele o sábio ou o filósofo, classe dos homens portadora de determinadas características que a torna apta ao exercício do governo demonstrando que a democracia é um governo sem governo, um governo sem fundamento, um governo no qual o fundamento se ausenta para se efetivar. A política própria da República afasta a poética do seu âmbito na mesma medida paradoxal que assume os seus traços fundamentais em uma relação opositiva radical. Em outras palavras, a cisão dos contrários, poética e política é gesto fundador e fundamento que os define simultaneamente e a seu campo disciplinar de a tuação. Depreende-se daí a necessidade de expulsar o poeta da república ideal pois, imerso no jogo da palavra, resiste à especialização e ao esquadrinhamento. Exerce ao mesmo tempo e potencialmente todas as funções e nenhuma, produz fantasmas e administra sucedâneos aos crédulos.

Revelando outra cena, em Fedro, diálogo longa mente analisado por Derrida em A farmácia de Platão, veremos a encenação de um debate sobre a escrita. Único diálogo que se passa fora dos muros da cidade, começa pela sedução da letra, o phármakon, remédio e veneno a depender de sua administração, conduzindo Sócrates às margens do rio Ilissos. O que Sócrates condena nas palavras trazidas por

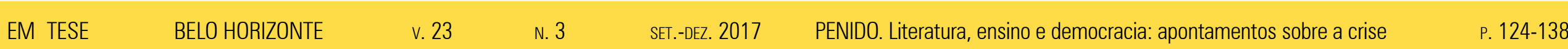


24. DERRIDA, A farmácia de Platão, p. $11-29$.
Fedro sob o manto é que aquele discurso se apresente sem a ingerência de um pai, que ele possa ser lido na ausência de uma voz autorizada. Simultaneamente, ao abandonar a cidade atrás dessas palavras sem rosto, dessa voz sem boca, a testa os males aliciadores da escrita, a sua potência oculta: não só mata a memória transportando ao papel o pensamento - pensamento-vivo contra a letra-morta -, a escrita desautoriza ao consentir o funcionamento de uma voz fantasmática autorizada por ninguém e sem a condução do pastor, reunindo em si a força de desencaminhar de abismar, de conduzir para fora do centro confortável da autoridade, da lei, da cidade. ${ }^{24}$

Ora, a potência oculta da escrita temida por Platão se ajusta perfeita mente à democracia, enquanto reino da lei abstrata em oposição à virtude do pastor, este último capaz de modalizar o remédio conforme a singularidade do paciente. A escrita faz uma incisão entre a virtude do pastor e a capacidade de funcionar em sua ausência, adquirindo novos usos e sentidos e, no limite, prescindindo da autoridade. Do mesmo modo que as idiossincrasias do homem privado (figura do leitor?) perturbam a harmonia do corpo social na República, a palavra circulando destituída de uma voz que a autorize, a voz do pastor em presença, aproxima o ato de ler-escrever do sorteio, do acaso, da possibilidade infinita de se distinguir de si. A voz sem pai representa essa ausência de fundamento que está na origem da democracia e da palavra escrita. É interessante lembrar o mecanismo do sorteio na democracia ateniense, desarra njando a ordem dos títulos, a hierarquia dos homens, a estrutura do Estado, fomentando um excesso de democracia condenável desde o início pelo texto platônico. A escrita é o excesso de democracia nas letras, a ausência de um funda mento último que a autorize a dispondo na ordenação das hierarquias, na série dos sentidos capturados pelos aparelhos de estado.

Quando Derrida afirma ser a literatura essa instituição que desborda a instituição ele se refere à maneira como a escrita literária esconjura os traços disciplinadores de qualquer instituição e ainda, repetindo Barthes, excede a instituição no seu impoder próprio. A literatura está sempre aquém e além das instituições porque é escrita fora da autoridade, do poder (Barthes), porque é passível de operar uma linguagem infinita (Foucault). Em outras palavras, a literatura nos parece o ponto cego do edifício institucional, restando a elas o disciplinamento regulando o acesso à palavra, recortando e contendo o excesso de democracia que ela representa (Derrida).

\section{LITERATURA, DEMOCRACIA, ENSINO}

Realizamos um trajeto que nos levou da língua fora do poder de Barthes, experiência apenas vislumbrada através da literatura, ao recrudescimento institucional do disciplinamento em Foucault, contrapartida com o intuito de

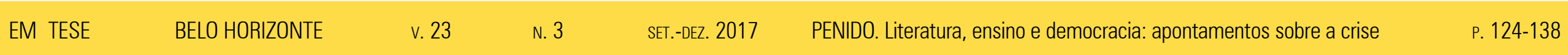


25. Não se trata de uma crítica à abordagem historicista que tem obviamente, inúmeros méritos, mas ao esqueleto programático desses estudos efetivamente chegado na escola, esvaziado por questões didáticas. conter seu poder de dissenso, de disseminação. Por último, tenta mos vincular a literatura à experiência democrática em Derrida, ou às condições de possibilidade da democracia.

Barthes, Foucault e Derrida permitem entender um problema urgente em nossos dias quando se inflaciona o discurso de uma crise das humanidades. Enquanto a literatura estiver subsumida sob as travas institucionais, recortada pelo poder, disciplinada pelos aparelhos escolares e pedagógicos, será sempre menos que literatura, sempre aquém de si mesma. A tensão entre o esvazia mento operado no ensino - ora convertendo as teorias que buscam recuperar o singular literário em heurística, ora adotando a co-ordenação em linhas diacrônicas nas quais a aventura da escrita é substituída pela combinação de nomes, obras e procedimentos ${ }^{25}$-, e a literatura liberta da sujeição em sua aventura de letra vazia, portanto ema ncipadora, democrática, permanecerá, à despeito de nossas tenta tivas, o impensável de nossa reflexão. No entanto, permanecer alijado desse debate, concedendo a outras áreas não específicas o protagonismo da reflexão - áreas em que a literatura não constitui fim e questão fundamental, mas meio ou pretexto com outros propósitos - apenas contribui para a inflação da crise. Interessa aos detratores das humanidades, ao discurso tecnocrático, ao neoliberalismo aplicado ao ensino esse vão do pensa mento, pois, alijada, a experiência literária se apequena na confraternização dos iniciados.

Se hoje a crise das humanidades divide espaço com a crise do ensino, não devemos pensar que se trata de crise de autoridade, pelo contrário, é sobre as ruínas de uma escola fundada no disciplinamento que a escrita literária deve propor uma transformação. Os planos curriculares nunca se adaptarão à literatura, a resposta disciplinar do século XVIII e a resposta liberal do séc. XXI permanecem apontando aquém do problema. Não é a literatura que deve se adaptar às instituições escolares, são as instituições que devem ser desmontadas de seu interior para comportarem o singular literário e as humanidades em geral, o impoder da literatura está, precisa mente, em mobilizar de dentro as instituições deixando a descoberto seus fundamentos. Os apontamentos preliminares aqui sugerem precisamente isso: herdamos um esqueleto escolar sustentado sobre o disciplina mento do poder-saber de séculos atrás enqua nto o discurso teórico avançava a passos largos descolando-se cada vez mais desses moldes incapazes de conter a força de singularização. A resposta tecnocrática, ensino útil, se alia aos processos de textualização a mpla, à linguística aplicada nesse ínterim a teoria deveria retomar o seu lugar enquanto discurso específico, único a solicitar verdadeiramente as instituições em seus fundamentos. O papel do teórico, hoje, em meio aos vários discursos escatológicos sobre a

\begin{tabular}{|c|c|c|c|}
\hline EM TESE & BELO HORIZONTE & v. 23 & N. 3 \\
\hline
\end{tabular}


literatura não deveria ser a lamentação ruidosa, pelo contrário, é preciso um esforço propositivo unindo a teoria da literatura ao seu ensino, cruzando prementes questões conceituais a práticas aptas a repensar em extensão os modelos institucionais herdados, muitas vezes, sem reflexão.

É preciso que a ausência de fundamento, o impoder, a força de dissenso na qual se principia a literatura e se sustenta a democracia, em sua contradição, constituam a forma da nossa questão e a força de nosso empreendimento. Escutar a língua fora do poder, leitmotiv de toda uma geração de teóricos, permitirá a neutralização dos efeitos de poder atuando no apequenamento da literatura nos bancos escolares. A crise da literatura e do ensino não é a sua morte, mas o seu início, o momento em que o pressentimento da ausência oferece as condições críticas para que a dissolução das instituições seja ao mesmo tempo um sintoma e um remédio. Tal nos parece nossa tarefa como teóricos.

\section{REFERÊNCIAS}

ABBAGNANO, Nicola. Dicionário de filosofia. Tradução de Alfredo Bosi. Revisão da tradução e tradução dos novos textos de Ivone Castilho Benedetti. 6. ed. São Paulo: Martins Fontes, 2012

BARTHES, Roland. Aula. Tradução de Leyla Perrone-Moisés. São Paulo: Cultrix, 1989
BLANCHOT, Maurice. A conversa infinita: a palavra plural. Tradução de Aurélio Guerra Neto. São Paulo: Escuta, 2001.

BLANCHOT, Maurice. A conversa infinita: experiência limite. Tradução de João Moura Jr. São Paulo: Escuta, 2007.

COMPAGNON, Antoine. $\mathbf{O}$ demônio da teoria: literatura e

senso comum. Tradução de Cleonice Paes Barreto Mourão. Belo Horizonte: Editora UFMG, 1999.

DERRIDA, Jacques. A farmácia de Platão. Tradução de Rogério Costa. 3. ed. rev. São Paulo: Iluminuras, 2005.

DERRIDA, Jacques. Marges de la philosophie. Paris: Minuit, 1972.

DERRIDA, Jacques. Essa estranha instituição chamada iteratura: uma entrevista com Jacques Derrida. Tradução de Marileide Dias. Belo Horizonte: Editora UFMG, 2014.

FOUCAULT, Michel. Vigiar e punir: nascimento da prisão. 25. ed. Petrópolis (RJ): Vozes, 2002.

FOUCAULT, Michel. História da loucura na idade clássica. 2. ed. São Paulo: 1987.

FOUCAULT. Michel. Estética, literatura e pintura, música e cinema (Ditos e Escritos v. III). Traduçao de Inês Autran Dourado. Rio de Janeiro: Forense Universitária, 2009.

PLATÃO. Diálogos. Tradução, textos complementares e notas de Edson Bini. São Paulo: Edipro, 2007. (v. I, II, III, IV, V, VI e VII).
EM TESE
BELO HORIZONTE
v. 23
N. 3
SET.-DEZ. 2017
PENIDO. Literatura, ensino e democracia: apontamentos sobre a crise
P. $124-138$

Ensino de Literatura 
RANCIĖRE, Jacques. A partilha do sensível: estética e política. Tradução de Mônica Costa Netto. São Paulo: EXO experimental org.; Ed. 34, 2005.

RANCIÈRE, Jacques. $\mathbf{O}$ inconsciente estético. Tradução de Mônica Costa Netto. São Paulo: Ed. 34, 2009.

RANCIÈRE, Jacques. O espectador emancipado. Tradução de Ivone C. Benedetti. São Paulo. WMF Martins Fontes, 2012.

RANCIÈRE, Jacques. O prazer da metamorfose política, Florianópolis, v. 1, n. 15, p. 25-32, out. 2010.

Recebido em 09-05-2018. Aceito em 14-06-2018. 